Original Research Paper

\title{
In-Plane Behavior of Infills using Glass Fiber Shear Connectors in Textile Reinforced Mortar (TRM) Technique
}

\author{
${ }^{1}$ Farhad Akhoundi, ${ }^{2}$ Graça Vasconcelos and ${ }^{2}$ Paulo Lourenço \\ ${ }^{1}$ Faculty of Architecture and Urbanism, Tabriz Islamic Art University, Iran \\ ${ }^{2}$ Department of Civil Engineering, ISISE, University of Minho, 4800-058 Azurém, Guimarães, Portugal
}

Article history

Received: 28-09-2017

Revised: $19-12-2017$

Accepted: 09-01-2018

Corresponding Author: Farhad Akhoundi

Faculty of Architecture and

Urbanism, Tabriz Islamic Art

University, Iran

Email: f.akhoundi@tabriziau.ac.ir

\section{Introduction}

The vulnerability of masonry infills to seismic actions such as Mexico City earthquake in 1985 (Miranda and Bertero 1989), Kocaeli (Turkey) earthquake in 1999 (Elnashai, 2000) Bhuj earthquake in 2001 (Jain et al., 2002), L'Aquila earthquake in 2009 (Braga et al., 2011) highlighted their needs for strengthening. In this regard, one possible solution is taken into account as using Fiber Reinforced Polymers (FRPs).

The special characteristics of FRP's such as good resistance to corrosion, lightweight, easiness of installation and good mechanical properties have lead its widespread use in the construction industry (Shrive, 2006). Different researchers studied the effect of FRP's on the in-plane (ElGawady et al., 2005; Erdem et al., 2006; Binici et al., 2007; Altin et al., 2008; Yuksel et al., 2010) and out-of-plane (Willis et al., 2010; Chen et al., 2012) behavior of infilled frames.

The scientific studies highlighted the ineffectiveness of FRP's in some conditions such as high and low temperatures. Also, FRP's are not applicable to wet surfaces and not compatible with some substrate materials such as clay (Papanicolaou et al., 2008).

To solve the problems related to the FRP's, organic binders can be replaced by inorganic ones such as cement based mortars. The fibers can be replaced by reinforcing meshes such as textile meshes with different continuous fibers. This results in the Textile Reinforced Mortar technique (TRM).

This newly developed technique (in 1980's) has been studied by few researchers (Papanicolaou et al., 2008; 2011; Elsanadedy et al., 2013; Bernat-Maso et al., 2014).

In the research conducted by Papanicolaou et al. (2008), twelve masonry wallets were tested in the out-ofplane direction cyclically to investigate the effectiveness of TRM versus Near Surface Mounted (NSM) and FRP techniques. It was concluded that the specimens strengthened with TRM technique demonstrated higher strength and displacement at failure with respect to specimens strengthened with FRP technique.

It was also observed that the effectiveness of NSM technique is generally related to the increase of deformability than the strength with respect to other techniques.

In the study conducted by (Bernat-Maso et al., 2014), the mortar in TRM technique is projected to the mortar surface to save application time. Then the samples were tested under three-point bending tests to compare the effectiveness of TRM with Textile Reinforced Sprayed Mortar (TRSM) techniques. 
It was concluded that TRSM technique resulted in the increase of strength and ductility of specimens with respect to TRM technique.

An innovative strengthening technique was proposed by Martins et al. (2015) by performing some bending tests on masonry wallets. Based on the results the strengthening material is designated as Braided Composite Rod (BCR) which results from a braiding process. A resin matrix was also applied to fill the voids and to give stability and homogeneity to the composite.

In the test conducted by Da Porto et al. (2015), the effectiveness of different parameters on the out-of-plane response of infilled frames using TRM technique were investigated. Those parameters are considered as (1) using special lime-based plaster with geo-polymer binder, (2) using bidirectional composite meshes applied with inorganic materials (TRM), (3) using anchors to fix the mesh to the rc frame. The test was performed as sequential in-plane and out-of-plane loading. The specimens were subjected to cyclic in-plane lateral drift of $1.2 \%$ and then they were loaded in the out-of-plane direction until collapse. The results showed the ineffectiveness of using special plasters in the increase of strength and stiffness of reference specimen. The main contribution is related to reducing the damage in the infill.

It was concluded that specimens strengthened with TRM technique demonstrated higher out-of-plane resistance (3.5 times) than the reference specimen.

\section{Experimental Program}

The experimental program was based on quasistatically testing of two infilled frames that were constructed similar to the construction methodology of south European countries in 1960s. The first specimen was assumed as control specimen and the second one was strengthened by using Textile Reinforced Mortar (TRM) technique in which the textile meshes was manufactured in our University. Taking into account the limited facilities at the laboratory of Civil Engineering at University of Minho and to avoid difficulties in handling full scale specimens, it was decided to design reduced scale specimens to represent the full scale rc frame with infill wall. The design of the reduced scale specimens was based on Cauchy's similitude law and test them according to the loading pattern that complies with FEMA-461 guidelines (FEMA461, 2007). Details about the prototype walls, the design of the reduced scale specimens, tests setups and loading pattern are presented in the next sections.

\section{Characterization of Prototype and Designing Reduced Scale Specimens}

The prototype of an rc frame with masonry infill was defined based on a study carried out for the characterization of the typical $\mathrm{rc}$ buildings constructed in
Portugal since 1960s (Furtado et al., 2014). From this study, a prototype with length of $4.50 \mathrm{~m}$ and height of $2.70 \mathrm{~m}$ was defined. The cross section of the rc columns was $0.3 \times 0.3 \mathrm{~m}$ and of the rc beams was $0.3 \times 0.5 \mathrm{~m}$. The masonry infills were mostly built as cavity walls composed of two leaves with horizontal perforated clay brick units. The external leaf has a thickness of $15 \mathrm{~cm}$ and the internal leaf has a typical thickness of $11 \mathrm{~cm}$, being separated by an air cavity of about $4 \mathrm{~cm}$.

An overview of the scaled reinforcement scheme of the rc frame and of the cross sections of columns and beams are shown in Fig. 1 and 2.

As mentioned before, two specimens were considered in the experimental campaign, namely one unstrengthened infilled frames assumed as control specimen (SIF-I(1\%)) and one strengthened specimens with TRM technique (SIF(DTRM)-I). It is stressed that the unstrengthened specimen was tested until imposed lateral drift of only $1 \%$ to be also used in out-of-plane testing campaign. As described before, the textile mesh used in the strengthened specimen was developed at University of Minho. The developed mesh is composed of a set of composite rods with an external polyester helicoidally braided with a reinforcing nucleus of glass fibers. The idea is that the braided rod can protect the reinforcing fibers and provide ductility after the rupture of the fibers (Martins et al., 2015), Fig. 3a. The bond between the external braid and the reinforcing fibers can be ensured in the manufacturing process by adding polyester resin during the braiding process or after the production of the composite braided rods by adding the resin over the external polyester manually (Martins et al., 2015). For the application on the masonry infills, the composite rod was composed of a braided structure with 15 multifilament of polyester with 11 Tex and one braided element with a simple structure consisting of 8 braided polyester yarns produced at the maximum speed of the production equipment $(1.07 \mathrm{~m} / \mathrm{min})$. The manufacturing of the meshes is carried out by interlacing the composite rods in two directions, assuming that the configuration of the connections of rods in two directions may promote an additional interlocking and can work as additional roughness, improving the bond adherence between the meshes and the rendering mortar, see Fig. 3b. The mesh has a tensile strength of about 55 $\mathrm{kN} / \mathrm{m}$ and stiffness of about $154 \mathrm{kN} / \mathrm{m}$.

The steel used for the construction of rc frame was of class A400NR, with a yielding tensile strength of $400 \mathrm{MPa}$ and for the concrete, a C20/35 class was adopted.

The developed reinforcing meshes used in the strengthened specimens consist of bi-directional glass fiber meshes.

\section{Construction and Strengthening of the Specimens}

The rc frames were constructed horizontally to make the concrete casting easier. 


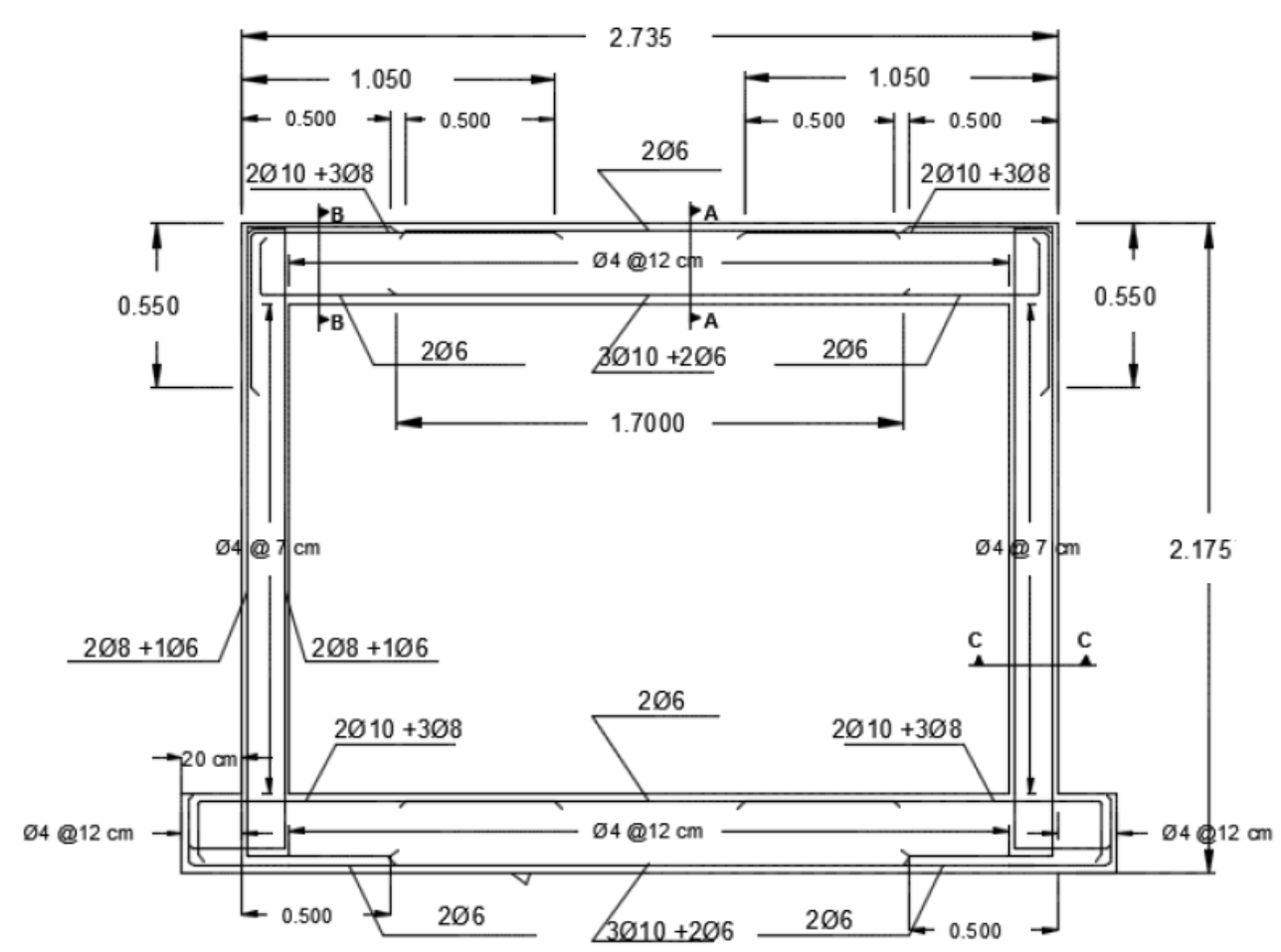

Fig. 1: Geometry and reinforcement scheme of the reduced scale rc frame (dimensions in meter)

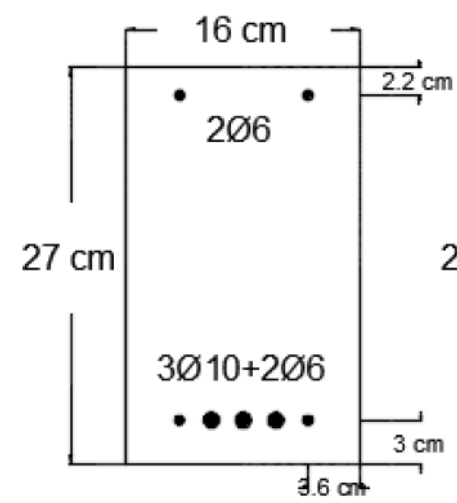

Section A-A

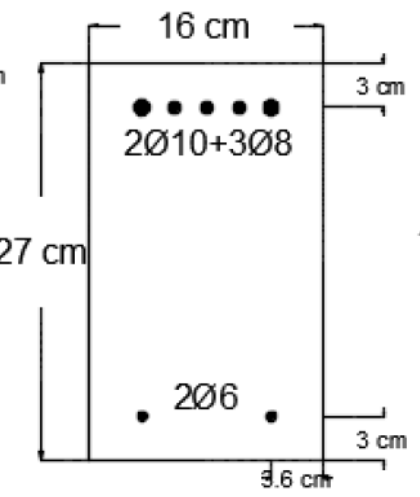

Section B-B

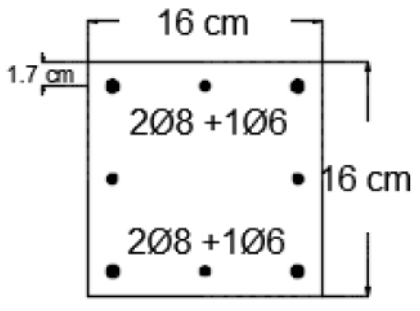

Section C-C

Fig. 2: Cross-sections of columns and beams in reduced scale rc frames

First, the wooden molds were placed in the horizontal position and then the reinforcement was mounted and placed inside the wooden mold. Due to the presence of little space between the longitudinal reinforcement of the beams in the reduced scale specimens, a concrete with a maximum aggregate of $9 \mathrm{~mm}$ with a characteristic compressive strength of $25 \mathrm{MPa}$ was used to ensure uniform concrete in the specimens, even in the places where little space exists between the reinforcements. The construction of the masonry infills was carried out in the storage area when the frames were placed and after finishing the construction of the walls, they were covered to be protected from the rain. The specimens were transported to the laboratory after 28 days from the construction day.

The rendering mortar used in the strengthened specimens was a pre-mixed commercial mortar indicated to be applied with the selected commercial textile mesh and was applied in both external surfaces of internal and external leaves. A multipurpose latex additive was added to the pre-mixed mortar aiming at improving its workability and consequently enhancing the mechanical and adhesive characteristics of cement-based rendering mortar. 

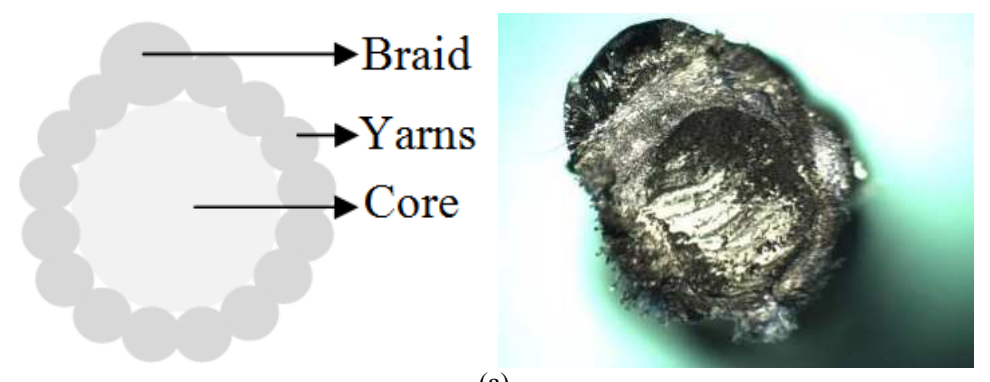

(a)

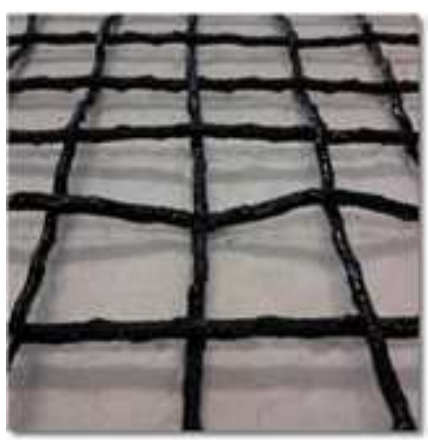

(b)

Fig. 3: Details of braided rods and meshes; (a) cross section of a braided mesh (Martins et al., 2015); (b) designed mesh

Additionally, L-shaped shear connectors were used to avoid any detachment of the rendering mortar from rc frame and masonry infill (Fig. 4a). Following steps were used to apply the rendering mortar to the specimens: In the first step the pilot holes were defined as shown in (Fig. 4a) to place the shear connectors in the specimens. In the second phase the holes were drilled and cleaned and then the plastic row plugs shown in Fig. $4 \mathrm{~b}$ were inserted in the holes (Fig. 5a). In the third step. First thin layer of about 5 mm of mortar was applied on the specimens (Fig. 5b). In the fourth step, chemical anchor was injected into the holes and L-shaped glass fiber connectors were inserted into them. Then in the fifth step the textile mesh was positioned on the first layer of mortar and finally in the last step the second layer of mortar was applied and rectified, see (Fig. 5c and d). The total thickness of the rendering was measured as approximately $20 \mathrm{~mm}$ in all the specimens. The application of the rendering in two successive layers enables the involvement of the textile mesh by the mortar and also adequate development of the adherence between them.

\section{Experimental Setup, Instrumentation and Loading Protocol}

The test setup for the in-plane testing of the specimens is shown in Fig. 6. The specimens were fixed to the laboratory floor to avoid any sliding and uplifting. The out-of-plane movement of the frame was also restrained by installation of L-shaped steel profiles $(\mathrm{L} 100 \times 100 \times 10 \mathrm{~mm})$ at each side of the upper concrete beam, which were bolted to the top steel frame, Fig. 6 b. Three rollers were placed on upper L-shaped profiles to minimize or even eliminate the friction between them and the upper reinforced concrete beam during in-plane loading.

Two vertical jacks applying the vertical load of 160 $\mathrm{kN}$, corresponding to $40 \%$ of the column's axial force capacity were placed on the top of the columns. A hydraulic actuator with $250 \mathrm{kN}$ capacity was installed to the reaction wall to apply the horizontal cyclic load.

The instrumentation of the specimens to capture all the deformation of the specimens is shown in Fig. 7. Total number of twenty-two LVDTs were used in the instrumentation process. From these LVDTS, four LVDTs were measuring the diagonal deformation of both internal and external leaves (L1, L2, L21 and L22). Two LVDTs were measuring the diagonal deformation of the surrounding frame (L19 and L20). Eight LVDTs (L3, L4, L5, L6, L7, L8, L9 and L10) were placed in the corners to measure the relative displacement of the infill with respect to the rc frame in the corners. LVDTs L11 and L12 were installed in the connection part of the infill to steel profile to measure any sliding and uplifting of the infilled frame with respect to the steel profile. Four LVDTs of L13, L14, L15 and L16 measured the sliding and uplifting of the steel profiles with respect to the strong floor. These measurements using the results of LVDTs of L11 to L16 were taken to control the reliability of the test setup. The LVDTs L17 and L18 measured the horizontal displacement of the upper beam of the reinforced concrete frame. 
The instrumentation plane of the strengthened specimens was shown in Fig. 8. Four LVDTs (L1 to L4) were measured the diagonal deformation of the external and internal leaves. Twelve LVDTS (L5 to L16) were installed to capture any possible detachment of rendering mortar in relation to the rc frame in the out-of-plane direction. To control the reliability of the test, six LVDTs (L17 to L22) were installed to monitor the possible uplifting and sliding of the specimen from ground and steel profiles. Finally, two LVDTs, L23 and L24, were placed on the top beam to measure the horizontal displacement at the top rc beam in the direction of the applied load.

In the in-plane static cyclic tests, pre-defined levels of displacements, which is in accordance with FEMA 461 (FEMA461, 2007) and is shown in Fig. 9, were imposed by the horizontal actuator in displacement control manner.

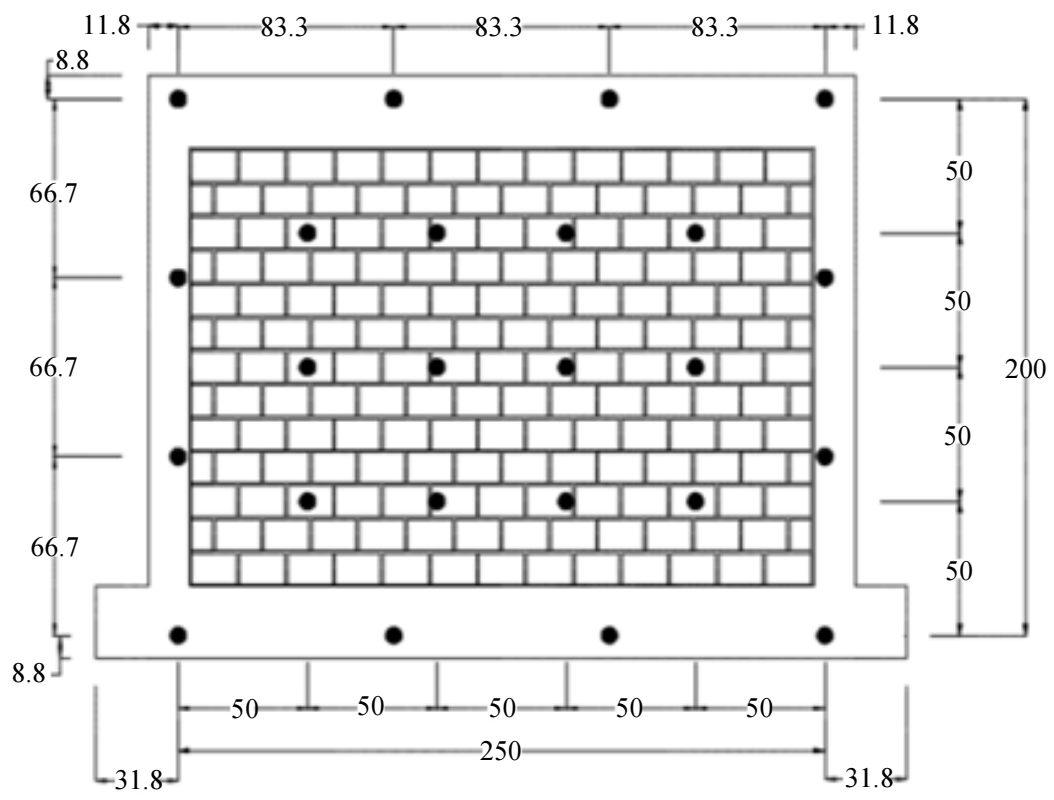

(a)

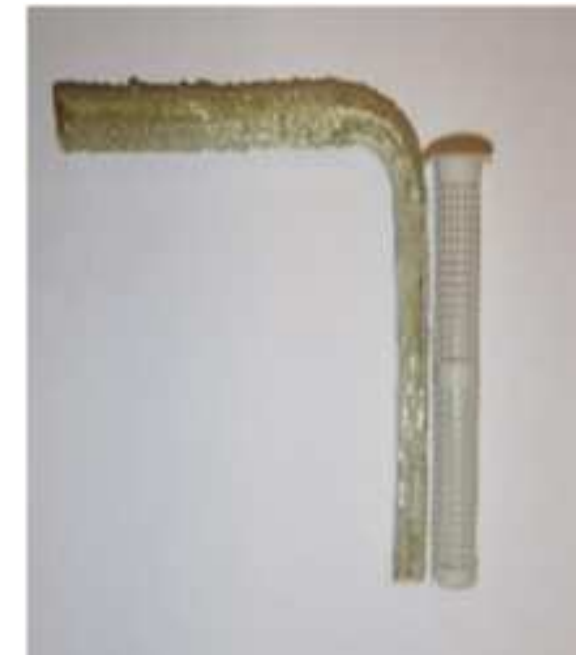

(b)

Fig. 4: Details of the mesh connectors; (a) pattern of the connectors (b) plastic row plug and glass fiber connector

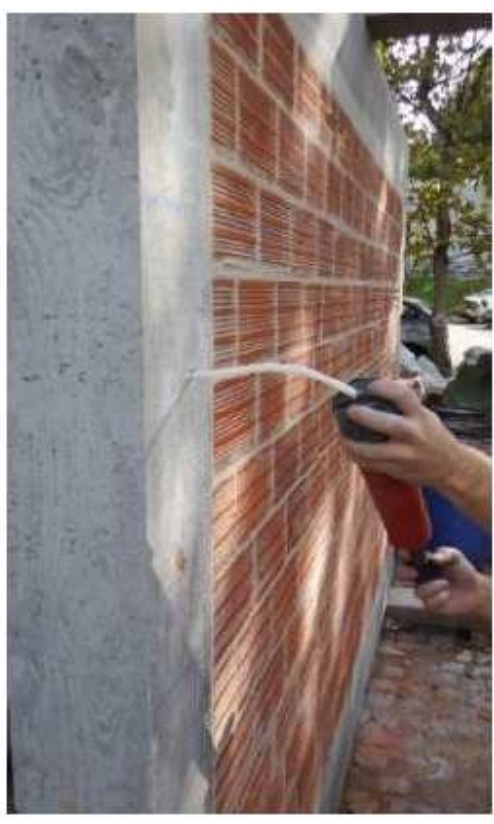

(a)

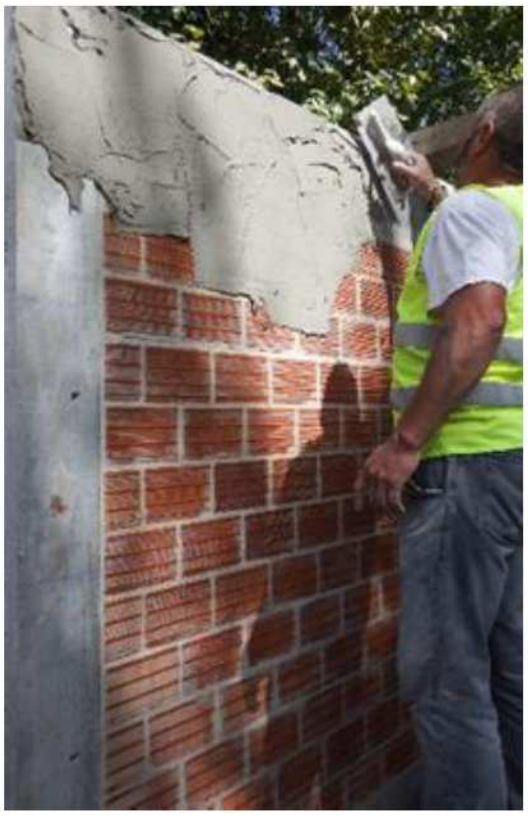

(b) 


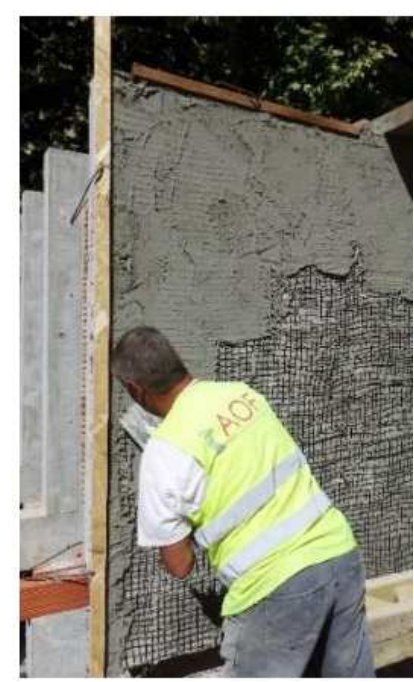

(c)

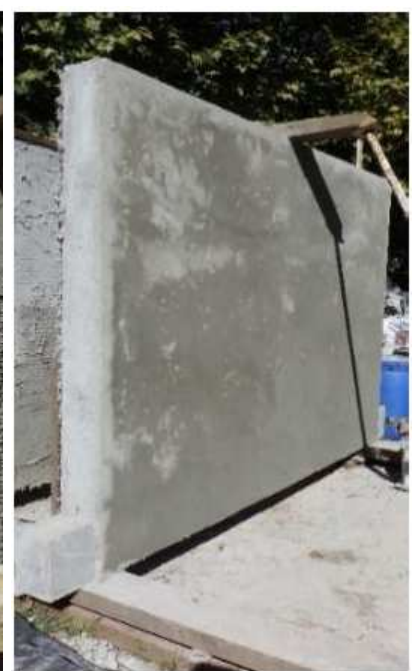

(d)

Fig. 5: Application of the reinforced rendering; (a) drilling the pilot holes (b) applying the first layer of mortar (c) positioning of the textile mesh and application of the second layer of mortar; (d) final aspect after rendering

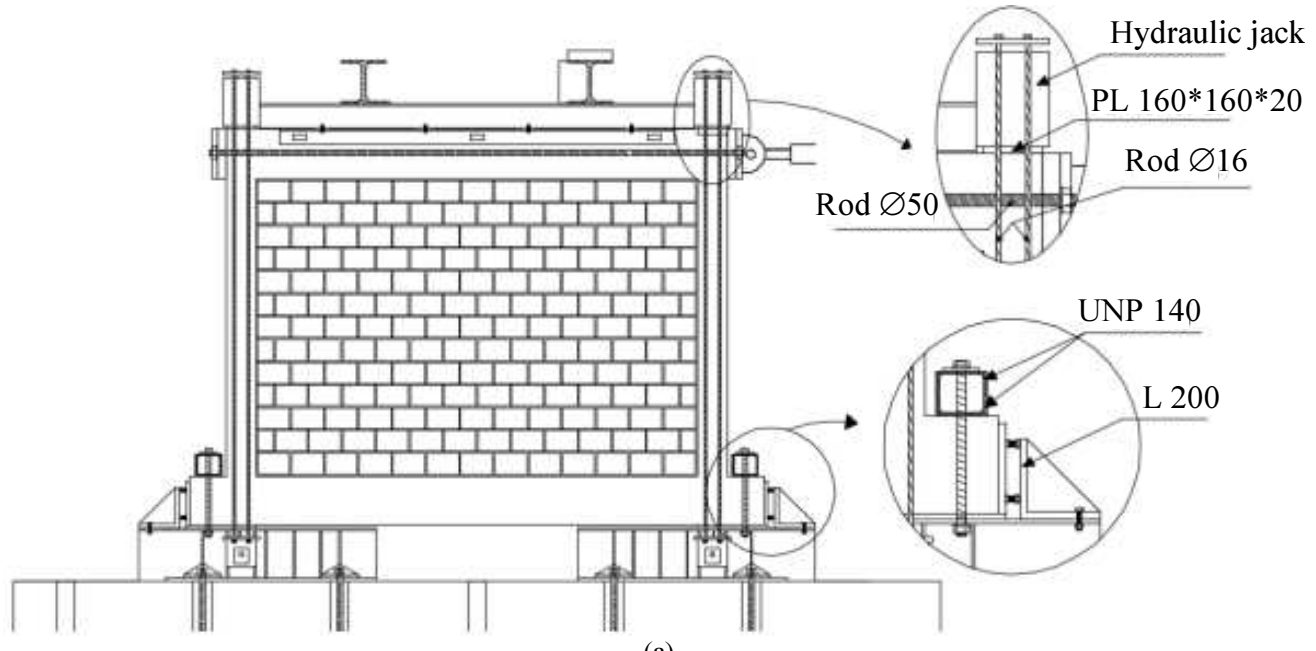

(a)

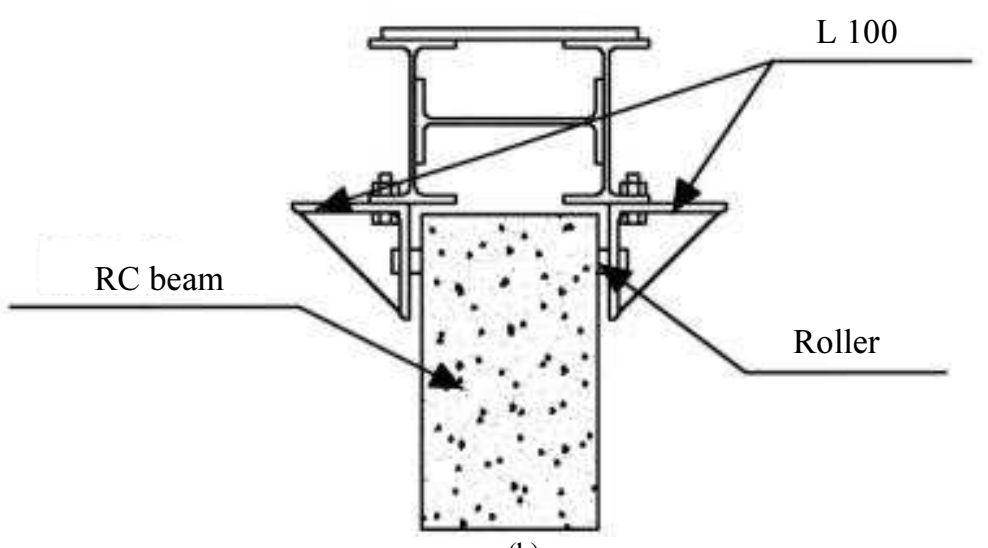

(b)

Fig. 6: (a) Test setup for in-plane cyclic loading (b) out-of-plane support of the upper beam in the in-plane testing 


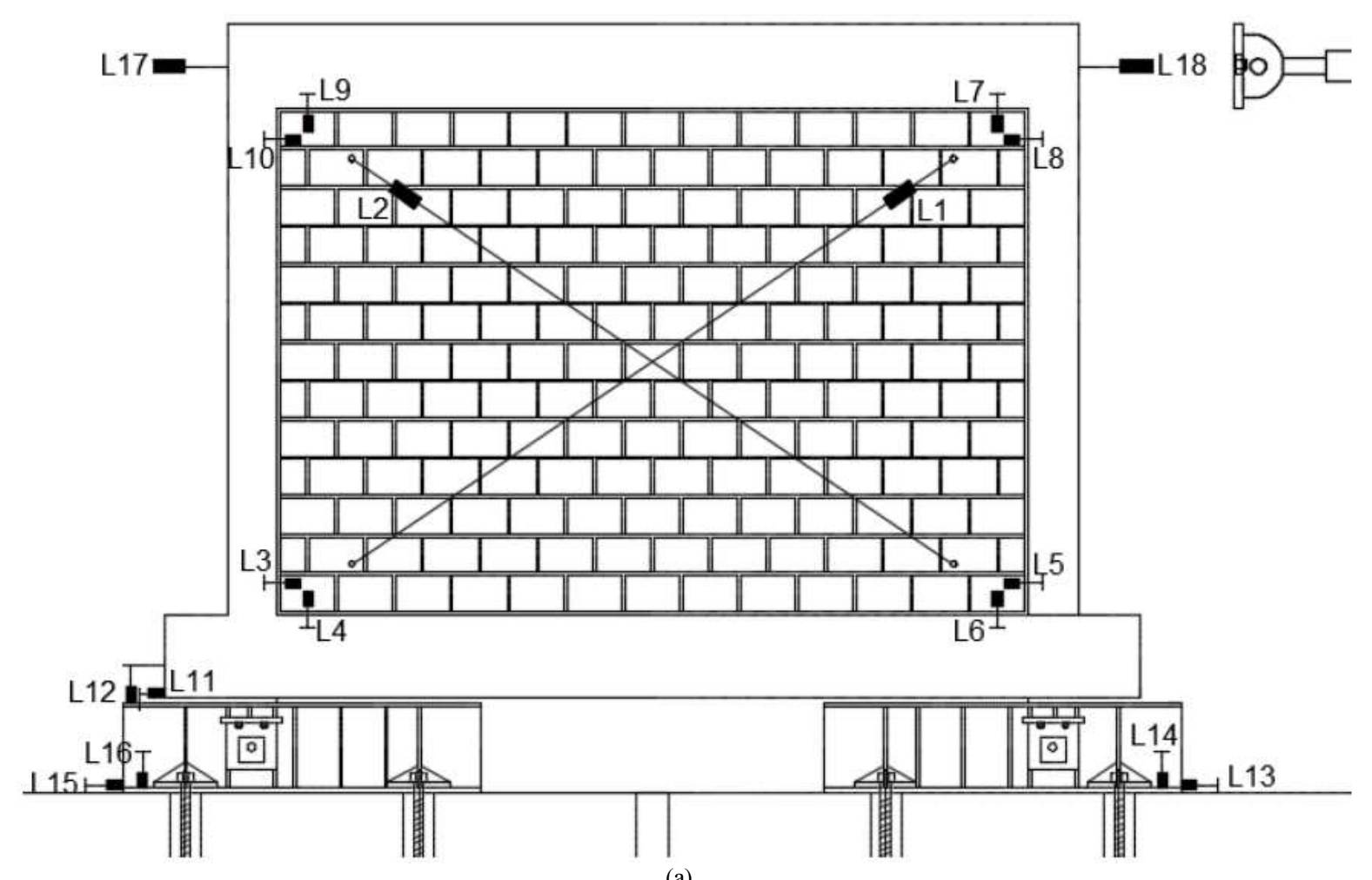

(a)
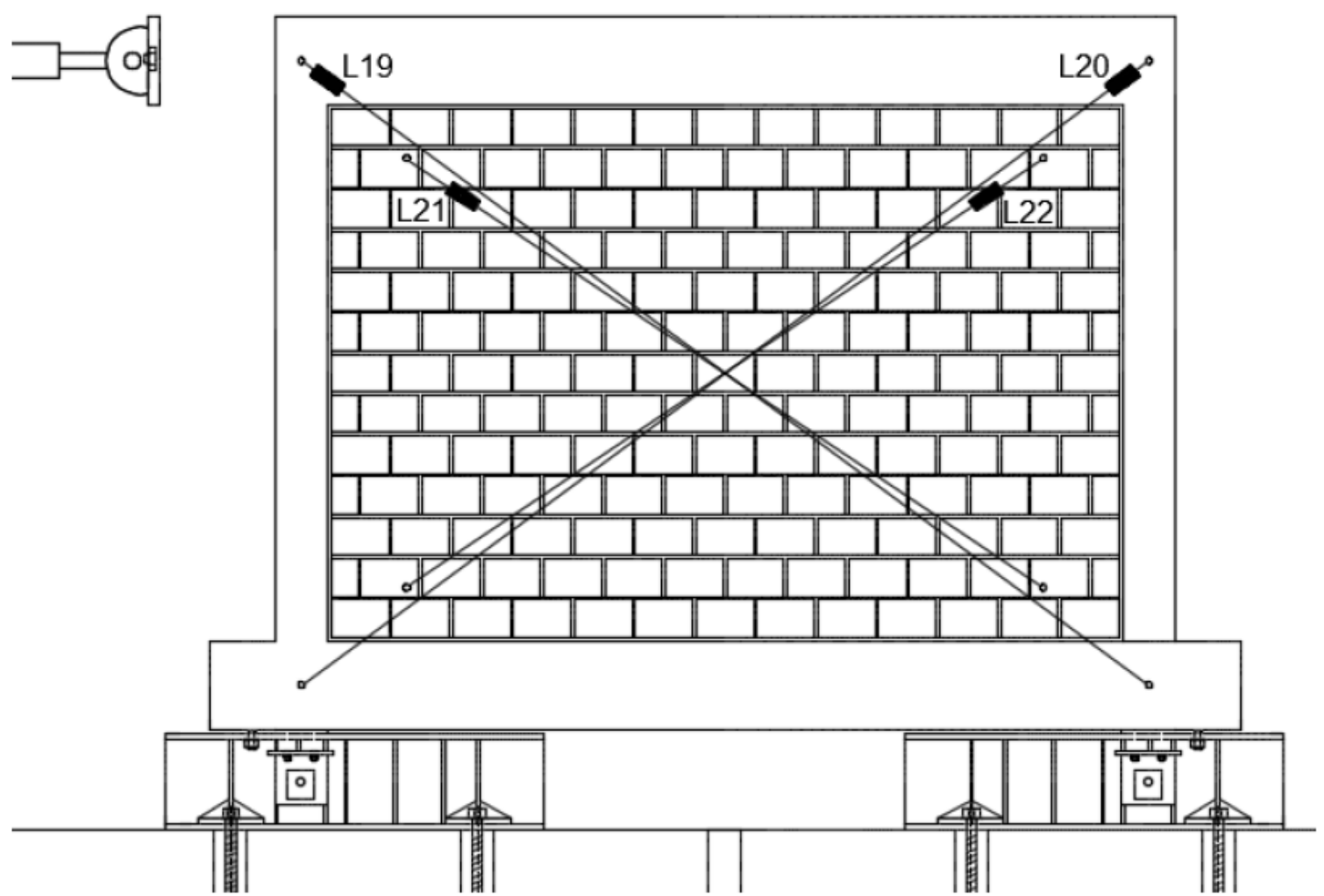

(b)

Fig. 7: Instrumentation for in-plane loading; (a) external leaf (b) internal leaf 

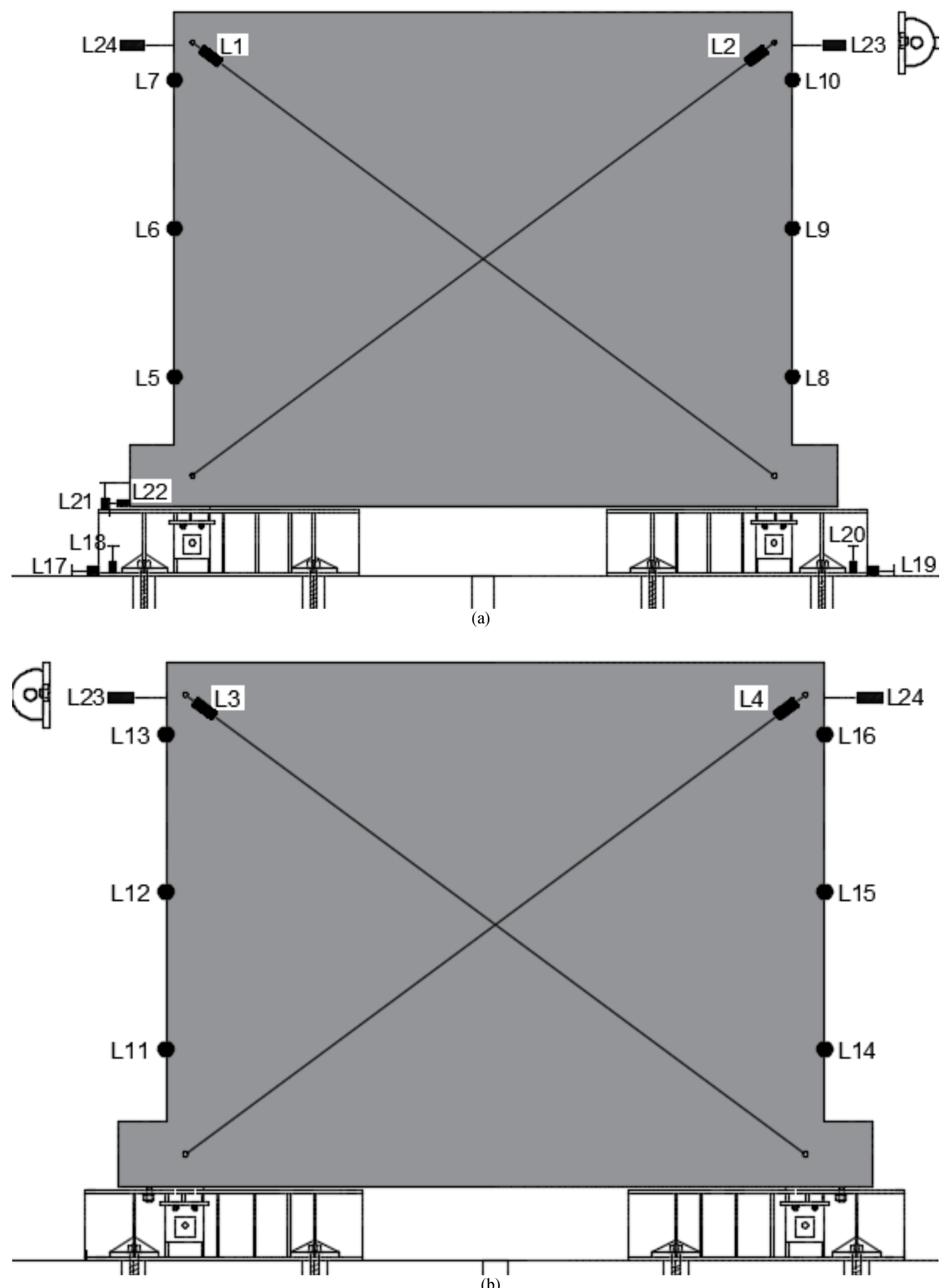

(b)

Fig. 8: Instrumentation of the specimen for in-plane loading; (a) external leaf (b) internal leaf 


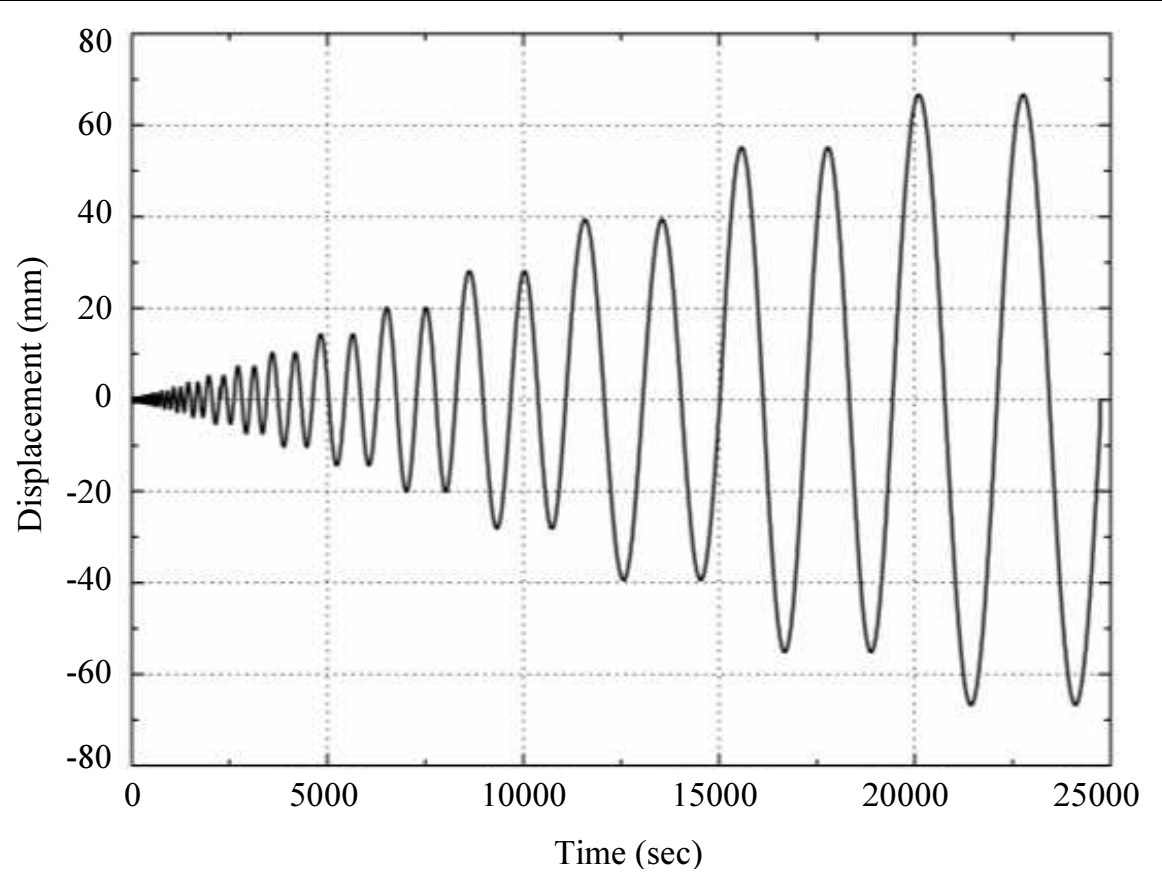

Fig. 9: Displacement protocol for in-plane testing

\section{Experimental Results and Discussion}

\section{Force-Displacement Diagrams}

The lateral force-displacement diagrams obtained for unstrengthened and strengthened specimens are shown in Fig. 10. It is clear that the strengthened specimen demonstrates better response in terms of initial stiffness and lateral strength. The increase in initial stiffness and lateral strength was reported as 43 and $58 \%$ in positive direction and 23 and $57 \%$ in negative direction. As it was mentioned previously, the unstrengthened specimen was tested until lateral drift of $1 \%$ to be used in another testing campaign investigating the effect of prior inplane damage on out-of-plane response. The positive direction is considered as the direction that the hydraulic actuator pushes the specimen whereas the negative direction is considered as the direction that the actuator pulls the specimen through two plates that were connected with two thick steel rods. The forcedisplacement diagrams are characterized by an initial linear behavior corresponding to the elastic behavior of the structure. After the onset of cracking, the nonlinear behavior is visible both through the nonlinearity of the force-displacement envelop and through the higher hysteresis corresponding to the development of damage and dissipation of energy.

The post-peak behavior is characterized by a progressive but smooth reduction on the lateral strength and stiffness, meaning that the damage is controlled and progressive.
It is clear that the strengthened specimen demonstrates better response in terms of initial stiffness and lateral strength. The increase in initial stiffness and lateral strength was reported as 43 and $58 \%$ in positive direction and 23 and $57 \%$ in negative direction.

\section{Crack Patterns}

The final cracking pattern developed in the cavity walls during the cyclic in-plane tests are shown in Fig. 11.

In the case of cracking pattern of unstrengthened infilled frame, it is characterized by: (1) separation of the infill from its rc frame. This separation starts from very early stages of lateral deformation; (2) diagonal cracking along the unit-mortar interfaces. After the separation between the masonry infill and the rc frame, the diagonal strut forms and diagonal cracking develops; (3) crushing of brick units adjacent to the top interface between the rc frame and masonry infill. It is observed that the cracking of the rc columns is more controlled in case of presence of the masonry infill. It is clear that the specimen (SIF$\mathrm{I}(1 \%)-\mathrm{B})$ presented more intense damage as most of the brick-mortar interfaces were cracked along with the cracking of RC frame in connection points of columns and beams. It is important to note that the cracking shown in Fig. 11 is regarding to the external leaf but the cracking in the internal leaf is very similar, indicating that that both leaves are effective in the resistance to the in-plane loading. This similar behavior exhibited by the internal and external leaves is also confirmed by the average shear distortion calculated for both internal and external leaves that presented in Fig. 12. 


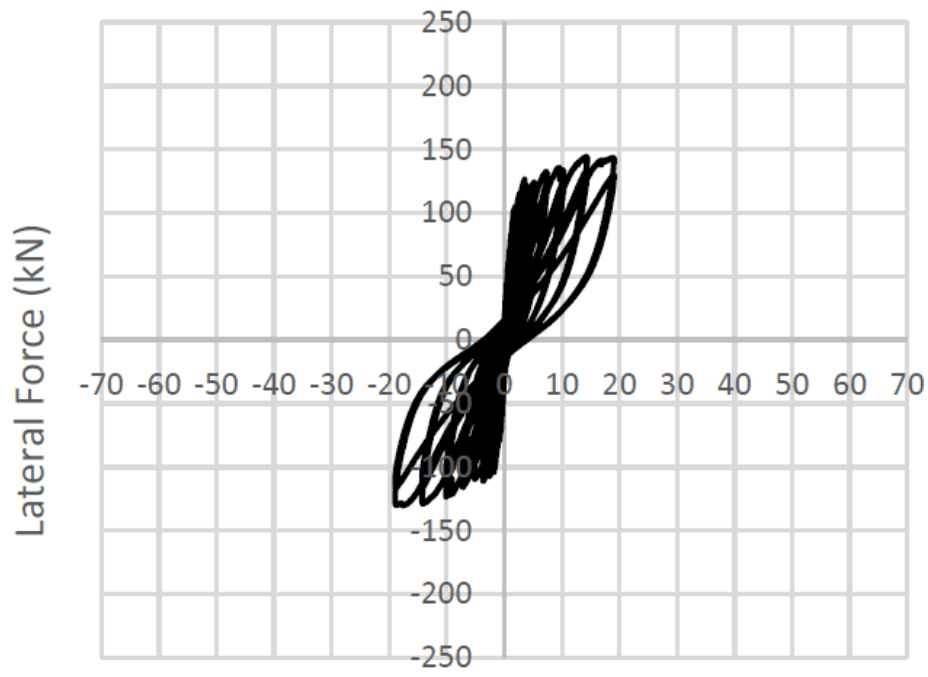

Displacement $(\mathrm{mm})$

(a)

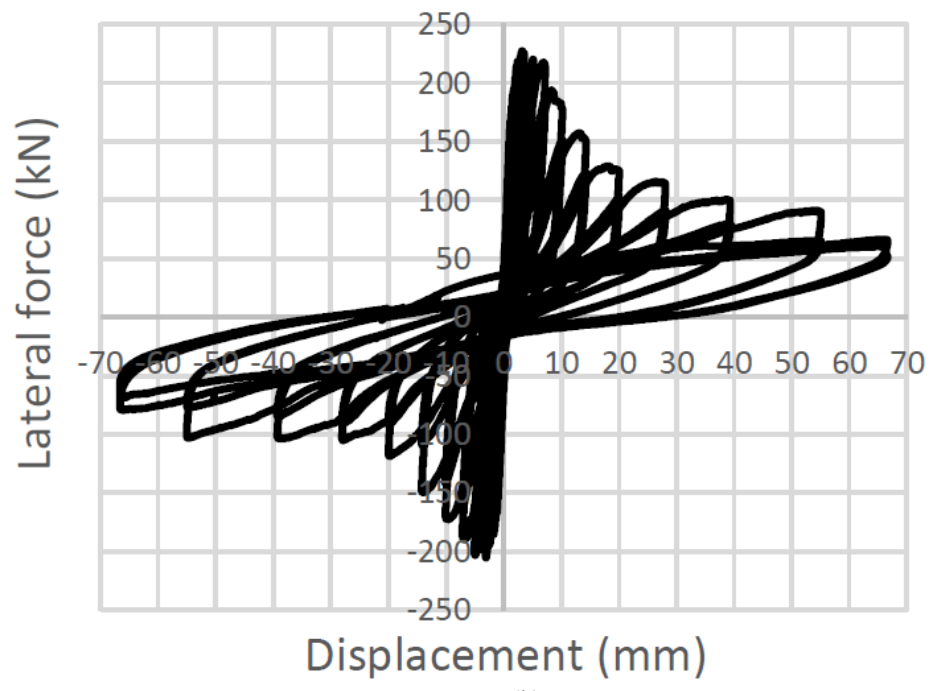

(b)

Fig. 10: Force-displacement diagram; (a) SIF-I(1\%) (b) SIF(DTRM)-I

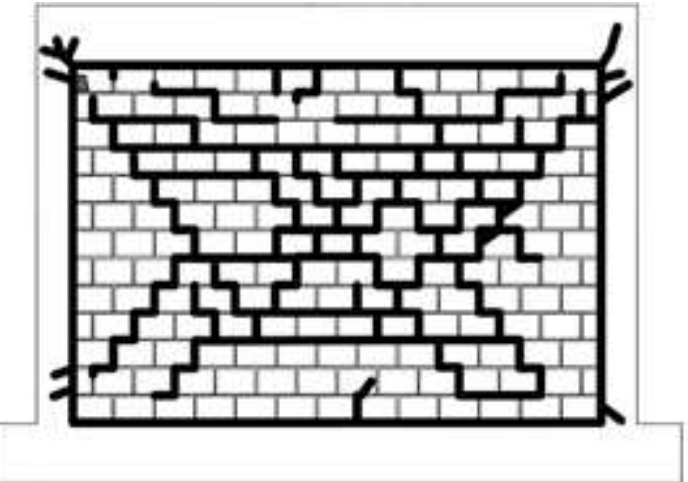

(a)

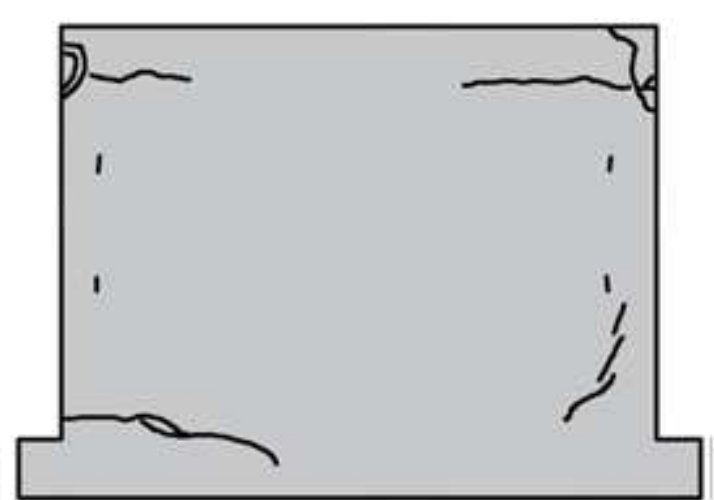

(b)

Fig. 11: Final cracking pattern of the (a) specimen SIF-I(1\%)-B; (b) specimen SIF(DTRM)-I 


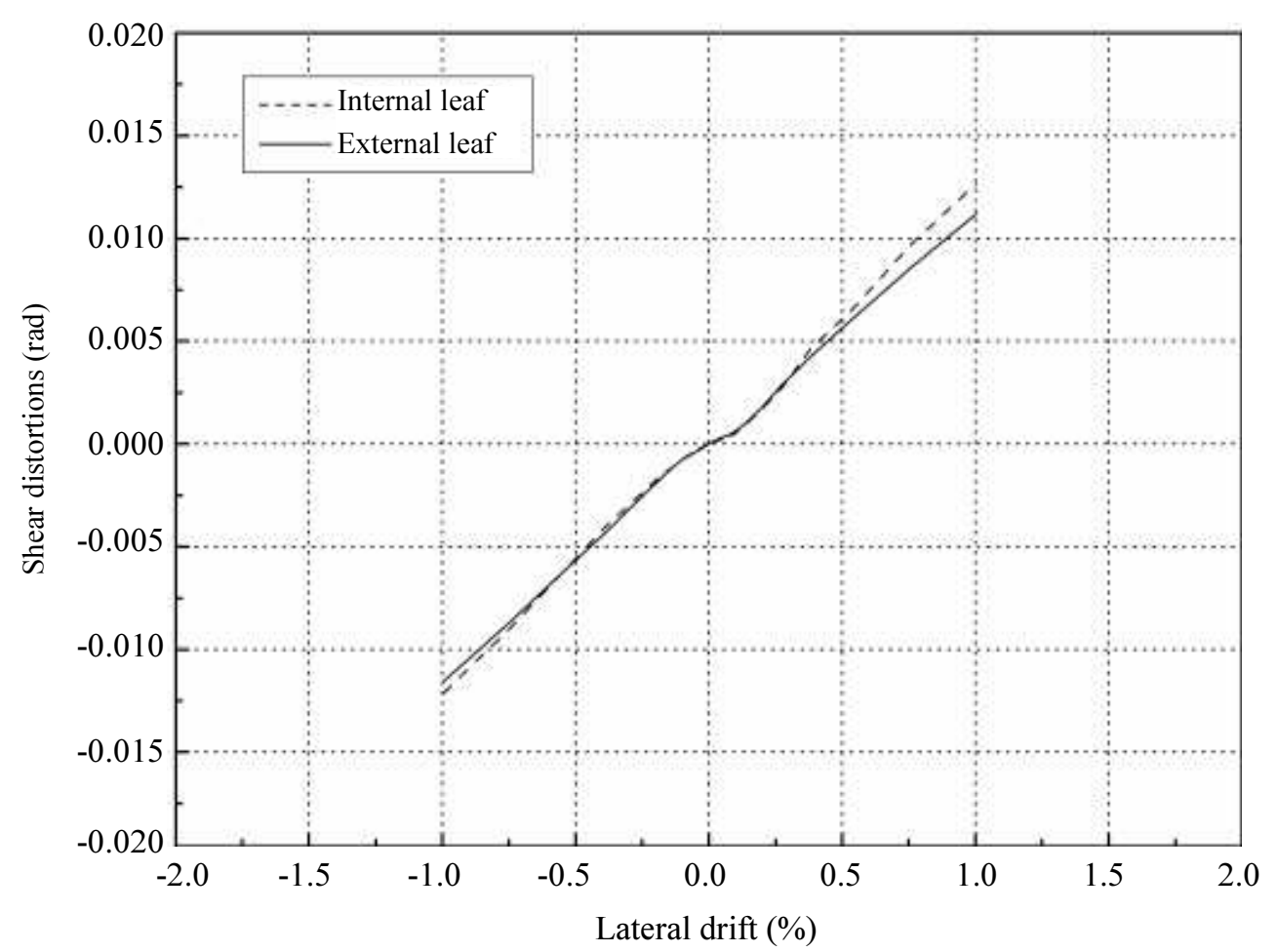

Fig. 12: Average shear distortions specimen SIF(DTRM)-I

The shear deformation of the masonry infill can be calculated based on the diagonal displacements measured by the diagonal LVDTs placed along the corners of masonry infill. The average shear distortion can be calculated using the following equation as:

$\gamma=\frac{\left(\Delta d_{1}-\Delta d_{2}\right) L_{d}}{2 L_{h} L_{v}}$

where, $\Delta d_{1}$ and $\Delta d_{2}$ are the length change of diagonals. The length $L_{d}$ is the initial length of the diagonals, $L_{h}$ is the initial horizontal length and $L_{v}$ is the initial vertical length.

For the cracking pattern of the specimen strengthened with bi-directional mesh composed of braided composite rods, only few cracks were developed in the reinforced mortar layer. Horizontal cracking was visible along the infill-rc frame interfaces. Some small cracks were also observed in the areas where the shear connectors were totally failed. The results showed that at lateral drift of $0.07 \%$ in both directions the strengthening mortar layers started to detach from the rc frame. This was observed from the results of LVDTs placed to measure eventual debonding of the mortar layer, Fig. 13. Based on this results, it seems that alternative shear connectors should be used in the rc fame as during the test brittle failure of the shear connectors were observed.
To note that shear connectors used for masonry infills did not face with any failure during the test. Investigations on the results of LVDTs installed on the height of the samples to measure the possible debonding of the rendering mortar from rc frame demonstrated that the detachment along the height of the specimens is similar. The appropriate preparation of concrete surface before applying the rendering mortar according to what is pointed out by Escrig et al. (2015) can be assumed as an alternative solution for enhancing the adherence of the rendering mortar to the reinforced concrete frame.

After the test, the reinforced mortar layer was removed mechanically to obtain information about the damage of the brick infill. It was seen that the masonry units crushed along the rc frame-infill interfaces, Fig. 14.

This could be related to the higher concentration of compressive stresses along the edge of the brick infill. It was also seen that no additional cracks were formed in the brick infill apart from the crushing in the bricks adjacent to the rc frame, indicating that the reinforced mortar layer acts as a damage controller by limiting the development of cracks in the brick infill. The crushing of the bricks along the interface is very similar between both strengthened specimens, even if it appears to be more significant in the specimen strengthened with the commercial textile mesh. 


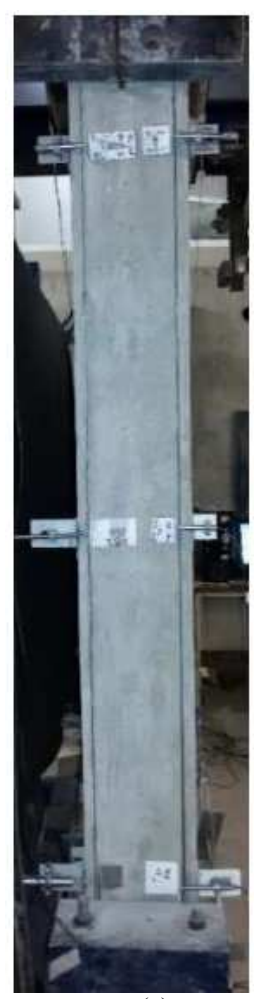

(a)

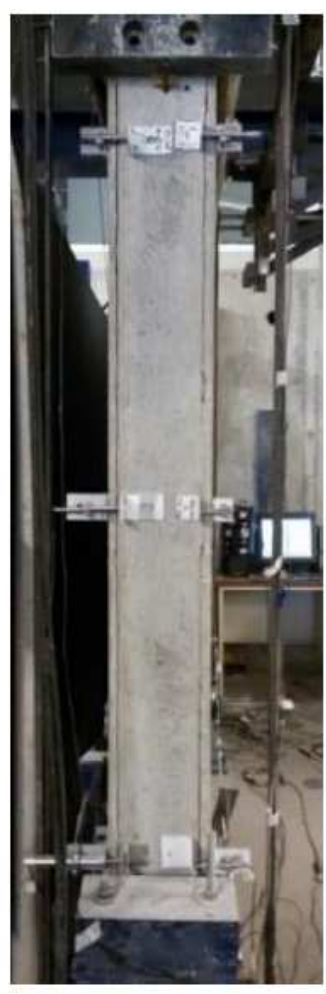

(b)

Fig. 13: Detachment of the reinforced mortar layer from the rc frame (a) specimen strengthened with commercial mesh at lateral drift of $0.27 \%$ (b) (a) specimen strengthened with developed mesh at lateral specimen strengthened with developed mesh at lateral

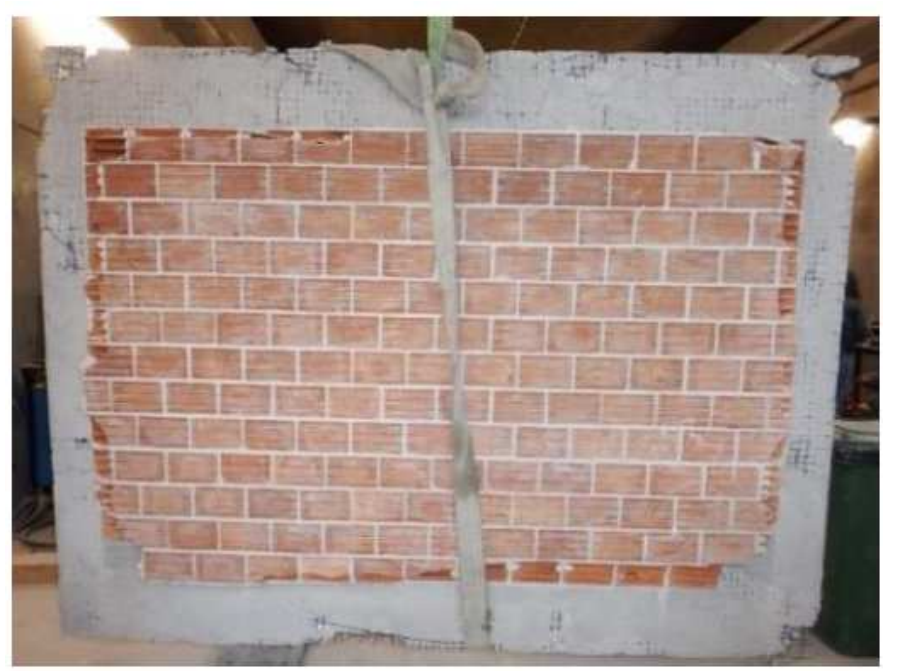

Fig. 14: View of the crushing of bricks of the infill after removing some parts of the retrofitting layer in specimen SIF(DTRM)-I

\section{Conclusion}

In-plane cyclic tests performed on strengthened and unstrengthened infilled frames revealed that:

- Using Textile Reinforced Mortar (TRM) technique enhances the initial stiffness and lateral strength of reference specimen. It seems that the effectiveness of this technique depends on the effectiveness of shear connectors used in the specimens fixing the retrofitting layer to the rc frame as no detachment was observed between rendering mortar and masonry infill

- It is clear that glass fiber shear connectors offered by commercial companies are not effective solutions 
to prevent the detachment between retrofitting layer and $\mathrm{RC}$ frame

- The textile meshes are also important to control the damage in the masonry infills. It is observed that much lower cracking was developed in the brick masonry infills strengthened with textile reinforced mortar

\section{Acknowledgement}

The authors would like to acknowledge the Portuguese Foundation for Science and Technology (FCT) for funding the research project ASPASSI Assessment of the safety and strengthening of masonry infill walls subjected to seismic action (POCI-01-0145FEDER-016898) (PTDC/ECM--EST/3790/2014).

This paper was presented at the 6th International Workshop on Design in Civil and Environmental Engineering held at the University of Cagliari during November $9-10-11,2017$.

\section{Author's Contributions}

All authors equally contributed in this work.

\section{Ethics}

This article is original and contains unpublished material. The corresponding author confirms that all of the other authors have read and approved the manuscript and there are no ethical issues involved.

\section{References}

Altin, S., Ö. Anil, M.E. Kara and M. Kaya, 2008. An experimental study on strengthening of masonry infilled RC frames using diagonal CFRP strips. Comp. Part B: Eng., 39: 680-693.

Bernat-Maso, E., C. Escrig, C.A. Aranha and L. Gil, 2014. Experimental assessment of textile reinforced sprayed mortar strengthening system for brickwork wallettes. Construct. Build. Mater., 50: 226-236.

Binici, B., G. Ozcebe and R. Ozcelik, 2007. Analysis and design of FRP composites for seismic retrofit of infill walls in reinforced concrete frames. Comp. Part B: Eng., 38: 575-583.

Braga, F., V. Manfredi, A. Masi, A. Salvatori and M. Vona, 2011. Performance of non-structural elements in RC buildings during the L'Aquila, 2009 earthquake. Bull. Earthquake Eng., 9: 307-324.

Chen, W.W., Y.K. Yeh, S.J. Hwang, C.H. Lu and C.C. Chen, 2012. Out-of-plane seismic behavior and CFRP retrofitting of RC frames infilled with brick walls. Eng. Structures, 34: 213-224.

da Porto, F., G. Guidi, N. Verlato and C. Modena, 2015. Effectiveness of plasters and textile reinforced mortars for strengthening clay masonry infill walls subjected to combined in-plane/out-of-plane actions /wirksamkeit von Putz und textilbewehrtem Mörtel bei der Verstärkung von Ausfachungswänden aus Ziegelmauerwerk, die kombinierter Scheiben-und Plattenbeanspruchung ausgesetzt sind. Mauerwerk, 19: 334-354.

ElGawady, M.A., P. Lestuzzi and M. Badoux, 2005. Aseismic retrofitting of unreinforced masonry walls using FRP. Comp. Part B: Eng., 37: 148-162.

Elnashai, A.S., 2000. Analysis of the damage potential of the Kocaeli (Turkey) earthquake of 17 August 1999. Eng. Structures, 22: 746-754.

Elsanadedy, H.M., T.H. Almusallam, S.H. Alsayed and Y.A. Al-Salloum, 2013. Flexural strengthening of RC beams using textile reinforced mortarExperimental and numerical study. Comp. Structures, 97: 40-55.

Erdem, I., U. Akyuz, U. Ersoy and G. Ozcebe, 2006. An experimental study on two different strengthening techniques for RC frames. Eng. Structures, 28: 1843-1851.

Escrig, C., L. Gil, E. Bernat-Maso and F. Puigvert, 2015. Experimental and analytical study of reinforced concrete beams shear strengthened with different types of textile-reinforced mortar. Construct. Build. Mater., 83: 248-260.

FEMA461, 2007. Interim testing protocols for determining the seismic performance characteristics of structural and nonstructural components.

Furtado, A., C. Costa, H. Rodrigues and A. Arêde, 2014. Characterization of structural characteristics of Portuguese RC buildings with masonry infill walls stock. Proceedings of teh 9th International Masonry Conference, Guimarães, Portugal.

Jain, S.K., W.R. Lettis, C.V.R. Murty and J.P. Bardet, 2002. Bhuj, India, Earthquake of January 26, 2001: Reconnaissance Report. 1st Edn., Earthquake Engineering Research Institute, Oakland, ISBN-10: 0943198119, pp: 398.

Martins, A., G. Vasconcelos, R. Fangueiro and F. Cunha, 2015. Experimental assessment of an innovative strengthening material for brick masonry infills. Comp. Part B: Eng., 80: 328-342.

Miranda, E. and V.V. Bertero, 1989. The Mexico Earthquake of September 19, 1985-performance of low-rise buildings in Mexico City. Earthquake Spectra, 5: 121-143.

Papanicolaou, C., T. Triantafillou and M. Lekka, 2011. Externally bonded grids as strengthening and seismic retrofitting materials of masonry panels. Construct. Build. Mater., 25: 504-514.

Papanicolaou, C., T. Triantafillou, M. Papathanasiou and K. Karlos, 2008. Textile Reinforced Mortar (TRM) versus FRP as strengthening material of URM walls: Out-ofplane cyclic loading. Mater. Structures, 41: 143-157.

Shrive, N.G., 2006. The use of fibre reinforced polymers to improve seismic resistance of masonry. Construct. Build. Mater., 20: 269-277. 
Willis, C.R., R. Seracino and M.C. Griffith, 2010. Outof-plane strength of brick masonry retrofitted with horizontal NSM CFRP strips. Eng. Structures, 32: 547-555.
Yuksel, E., H. Ozkaynak, O. Buyukozturk, C. Yalcin and A.A. Dindar et al., 2010. Performance of alternative CFRP retrofitting schemes used in infilled RC frames. Construct. Build. Mater., 24: 596-609. 